\title{
Managing postgraduate education
}

\author{
Susan Whyte
}

There have been many changes in postgraduate education in psychiatry over the past 15 years. The Royal College of Psychiatrists was ahead of most other Medical Royal Colleges in organising supervised training schemes which took into account the educational needs of the trainee as well as providing an appropriate service to patients. The approval exercise, with inspection of both basic specialist and higher specialist training schemes, was introduced more than 20 years ago. Prior to the introduction of 'Achieving a Balance' - Plan for Action (Department of Health, 1987), the senior house officer (SHO) and registrar grades in psychiatry were more or less interchangeable, although those in registrar posts tended to rotate outwith their base hospital and gain experience in the sub-specialities.

\section{The development of psychiatric training}

'Achieving a Balance' led to a reorganisation of training in psychiatry with a split between $\mathrm{SHO}$ and registrar-level SHOs being based in one hospital or a few hospitals, and career registrars rotating through training schemes involving teaching hospitals and other psychiatric services which were more geographically distant. This was useful in providing different training experiences but led to a somewhat artificial split between the grades. The requirement for passing from the SHO to the career registrar grade was obtaining Part I of the MRCPsych, and to the senior registrar grade, it was MRCPsych Part II.

The introduction of Hospital Doctors: Training for the Future ('Calman report'; Department of Health,
1993) changed the organisation of training much more radically. Training was divided once again into two levels, SHO and specialist registrar (SpR), which led to the re-amalgamation of the SHO and career registrar grades, the possession of Part II of the MRCPsych being an essential requirement for moving to the SpR grade. In theory, this made SHO training slightly longer than other specialities, but in practice this has proved not to be a significant problem in view of the manpower problems in some other specialities with an excess of SHOs. With the bringing forward of the MRCPsych examination by six months, allowing trainees to sit after two and a half years, psychiatrists are not disadvantaged by the length of their SHO training.

Although there were some teething problems with the introduction of the SpR grade, it has gone smoothly on the whole in psychiatry, despite some problems in funding additional posts. For example, in the west of Scotland, we were able to increase our SpR numbers from 28 to 52 , partly by additional funding and partly by conversion of SHO posts to $\mathrm{SpR}$, while persuading the trusts to fund replacement SHOs. In some areas, it has not proved possible to do this and $\mathrm{SpR}$ numbers have increased at the expense of SHO posts, despite some additional central funding.

\section{Where are we now?}

Training schemes have now emerged from the Calman report, and the SpR grade is working well. The initial anxieties that SpRs would not carry out enough clinical work have proved unfounded, and the protected time of two research sessions and two special interest sessions in some specialities is generally well implemented. Special interest

Susan Whyte is a consultant psychiatrist supervising liaison psychiatry at the Victoria Infirmary. She is Educational Co-Ordinator at the Academic Centre, Gartnavel Royal Hospital (Glasgow G12 OXH) where she is responsible for coordinating between the Royal College of Psychiatrists, the Postgraduate Dean and the Greater Glasgow Community \& Mental Health Services NHS Trust, dealing with issues in relation to training and education. 
sessions often involve some clinical work and audit, and research projects may be related to the placement in which the trainee is working at the time. The increased numbers of higher trainees has been useful in taking some of the pressure off consultant rotas, where covering an $\mathrm{SpR}$ is somewhat less onerous than covering an SHO. This increase in numbers should deal with the large number of consultant vacancies over the next few years.

\section{Organisation of postgraduate training}

\section{Specialist training authority}

The overall supervision of specialist training is through the Specialist Training Authority (STA), which is responsible for awarding the Certificate of Completion of Specialist Training (CCST) and for maintaining the General Medical Council's Specialist Register. It carries out its roles in close consultation with the Medical Royal Colleges, which currently supervise the training schemes, although theSTA may develop a more active role in monitoring the approval and supervision process in relation to specialist training.

\section{Role of the postgraduate dean}

One of the major changes of the Calman reforms was the increasing involvement of postgraduate deans in the organisation of training schemes for all specialities. In Scotland, $100 \%$ of the salary of trainees is funded by the postgraduate dean, and the trusts are only responsible for payments for additional duty hours. Generally, this process is working well. Elsewhere in the UK, the postgraduate dean holds $50 \%$ of funding for training posts.

Information on SpR training is available in the 'orange book' - A Guide to Specialist Registrar Training (Department of Health, 1996, updated 1998). The main supervision process through the postgraduate dean's department is the Record of In Training Assessment (RITA), which is completed at yearly intervals for those in higher training. Satisfactory completion of each assessment allows progress to the next year of training and if there are problems, these can be identified and dealt with - the most severe cases requiring a repeat of the year of training.

Postgraduate deans have involvement in the assessment of new training posts and the supervision of training schemes, although much of this is delegated to the speciality training committees, which oversee training in each speciality. This system allows opportunity for flexible training, for overseas doctors to obtain fixed-term training appointments and for some movement of trainees between deaneries for appropriate reasons (see Box 1).

Postgraduate deans fund and oversee study leave and this has led to difficulties in some places where study leave funding has not been at a suitable level to provide the opportunity to attend training courses and meetings. The Committee of Postgraduate Medical Deans (COPMeD) is currently looking at study leave guidelines for the deaneries.

\section{Role of the College}

One of the main roles of all Medical Royal Colleges is to organise training in their speciality, including the examination process, the development of basic and higher specialist training schemes and the overall coordination of postgraduate education within the speciality.

\section{College committees}

Overall supervision of training and standards within the College is through the Court of Electors,

\section{Box 1. Organisation of training in psychiatry in the regions \\ Postgraduate dean \\ Speciality training committee \\ Chairman - attends Committee of Speciality Representatives for all medical specialities}

Membership of Committee

College tutors

Speciality tutors and programme directors University representatives

Trainees' representatives (higher and basic specialist training)

Regional adviser, psychology \& continuing professional development representative

Postgraduate dean or representative

In large schemes each speciality may have a small committee overseeing the organisation of its training. Some deaneries have separate training committees for basic and higher specialist training. The detailed committee structure varies from region to region 
chaired by the President and having various subcommittees. The main educational officer of the College is the Dean, who has responsibility for educational matters. There has been a re-organisation of College committees which has streamlined the administrative process for educational issues. The Basic Specialist Training Committee supervises training at SHO level and the Higher Specialist Training Committee supervises training at $\mathrm{SpR}$ level. Both these committees are answerable to the Court of Electors, whereas previously the Higher Training Committee was a joint committee between the universities and the College, and was not incorporated in the College structure (see Box 2).

\section{Approval exercise}

One of the main developments in psychiatric training over the years has been the approval exercise, both at SHO and SpR level, looking at training schemes and individual posts, as well as overseeing the MRCPsych courses and other aspects of training. The Royal College of Psychiatrists was one of the first to set up this exercise and many of the other Colleges have followed our example. The close relationship between psychiatry and general practice, particularly in training at SHO level, has enabled us to develop joint approval exercises between the two Royal Colleges.

\section{Basic specialist training}

\section{Organisation of schemes}

Psychiatry is one of the few specialities in which basic specialist training has been closely supervised for many years. The approval exercise has involved the inspection of training schemes in relation to their educational quality, individual training posts and the organisation of rotations between specialities. Training schemes should have different placements in general adult psychiatry, old age psychiatry, substance misuse, rehabilitation, child and adolescent psychiatry and learning disability. Placements in liaison and forensic psychiatry may be available, and a diversity of placements within schemes should be encouraged. Basic training, usually in the first year or 18 months, is within general psychiatry and its sub-specialities, or old age psychiatry. Exposure to the other sub-specialities is more appropriate after taking the MRCPsych Part I examination and prior to applying for an SpR post. Mandatory experience, for at least six months prior to gaining an SpR post, in either learning disability or child and adolescent psychiatry, or a combination of the two, will soon be introduced. The more training available within a scheme, the easier it is for trainees to decide their choice of speciality. The recent increase in SHO recruitment may be related to trainees in other specialities seeing that psychiatric training is well organised and supervised.

\section{MRCPsych examination}

The MRCPsych acts as an exit examination at the end of the SHO grade, allowing progression to higher specialist training. There has been much discussion among the Medical Royal Colleges about the timing of examinations. The main disadvantage of the MRCPsych is that some trainees, after spending considerable time in psychiatry, will not pass the examination. However there are options to move into staff grade posts and it is useful for people who work in other specialities, particularly general practice, to have training in psychiatry.

MRCPsych Part I can be taken after one year's training in psychiatry and must include at least six months in a core placement of general psychiatry, the second placement either being within general or old age psychiatry.

Box 2. Royal College of Psychiatrists Committee structure

$$
\text { President }
$$

$\begin{array}{ll}\begin{array}{l}\text { Dean (main } \\ \text { educational officer) }\end{array} & \begin{array}{l}\text { Registrar (main } \\ \text { administrative } \\ \text { officer) }\end{array} \\ \begin{array}{l}\text { Court of Electors } \\ \text { Educational } \\ \text { committees }\end{array} & \begin{array}{l}\text { Administrative } \\ \text { committees }\end{array}\end{array}$

Main educational committees:

Education Committee - oversees all educational policy

Basic Specialist Training Committee-previously Central Approval Panel

Higher Specialist Training Committee previously Joint Committee on Higher Psychiatric Training

Examinations Committee

Collegiate Trainees Committee

College Tutors' Committee

CPD Committee 
MRCPsych Part II can now be taken after two and a half years in psychiatry with experience in all the sub-specialities of psychiatry being acceptable. Up to six months' placement in another speciality can be acceptable, for example general medicine, neurology, medical geriatrics or general practice.

Detailed information regarding the criteria for application for the examination is available from the College's Examinations Department, as is a curriculum for the MRCPsych. All training schemes run MRCPsych courses, which provide academic training and which all trainees must attend in order to sit the examination. Additional training in interview skills, critical appraisal skills and research is available in most schemes. Some schemes also run Masters degree courses, providing both academic training and the opportunity to complete and submit a piece of research.

\section{Role of the College tutor}

A College tutor (previously clinical tutor) is appointed in each training scheme to oversee basic specialist training at SHO grade, including rotational placements and organisation of an internal teaching programme, including case presentations, journal clubs and seminars. The College tutor acts as a coordinator for educational activities within the scheme and provides individual assessment and advice, as well as ensuring that the educational supervisor provides appropriate clinical supervision and faceto-face contact with the trainee on a weekly basis for one hour. The College Tutors' Handbook (Royal College of Psychiatrists, 1995) gives details of the role and responsibilities of tutors.

\section{Higher specialist training}

The major changes in relation to the Calman reforms have been in higher specialist training. This has been to a lesser extent in psychiatry than some other specialities because the MRCPsych continues to act as an entrance examination to higher training. However, the increase in SpR numbers and the more formal process of assessment introduced through the RITA system has led to changes in the organisation and monitoring of all schemes. My own experience has been in the Glasgow \& West of Scotland Higher Training Scheme, which covers half the population of Scotland.

The availability of experience will vary between schemes depending on the size and the ratio of urban to rural catchment areas. Some have a higher university and research profile and others provide more varied clinical experience. Although a large scheme proves an administrative headache, it does provide more variety of experience for trainees, and makes it easier to cater for individual needs.

\section{Organisation of higher training - the role of the programme director}

Detail of the organisation varies among regions. The chairman of the specialist training committee in psychiatry normally has responsibility for overseeing the organisation of the scheme for all specialities and the relationships between them. Each of the five sub-specialities also has a programme director responsible for organising training within their own speciality. This individual may also fulfil the role of speciality tutor for basic specialist training, but this varies between regions. The organisation of postgraduate training through the postgraduate dean's office is shown in Box 1. The chairman of the speciality training committee and the programme directors in the speciality have responsibility for organising $S p R$ reviews, academic programmes and trainee placements, and for providing advice to trainees.

\section{Speciality training}

Higher specialist training in the specialities is supervised through the College by the Speciality Advisory Committees which report to the Higher Specialist Training Committee. Each speciality has its own committee, for example GOAPSAC (general and old age) and CAPSAC (child and adolescent psychiatry). In the regions, the speciality tutors/ programme director for each speciality will oversee the organisation of training. The Higher Specialist Training Handbook produced by the Royal College of Psychiatrists (1998) details the nature of higher training required in all the specialities.

\section{General psychiatry}

Experience in general psychiatry constitutes the core for general psychiatry trainees, but can also be part of the training in old age psychiatry and the psychiatry of learning disability. General psychiatric trainees may also wish to spend up to a year in other psychiatric specialities (e.g. forensic psychiatry), or develop a special interest in substance misuse, rehabilitation, or liaison psychiatry, with recognition of this on the Specialist Register. Experience in community psychiatry is now regarded as an integral part of general psychiatry and all trainees should have both community and in-patient work, preferably in both a central and peripheral setting. 


\section{Old age psychiatry}

There has been a recent change in the regulations for old age psychiatry in that trainees appointed after 1 January 1997 no longer need to spend one year in general psychiatry. However, many speciality tutors advise trainees to spend time in general psychiatry and to expand their special interest training, for example, in neurology, neuroimaging or dementia services, to gain a wider experience.

Forensic psychiatry

Full-time training in forensic psychiatry involves placements in a variety of forensic clinic and institutional settings, and an attachment to a special hospital. Because of the variations in the Mental Health Act in the various parts of the UK, trainees may wish to have a short-term placement elsewhere.

\section{Learning disability}

Most placements are community team-based. Training programmes in learning disability can include up to one year's general psychiatry, and many trainees opt for dual certification and special interest options, including units in genetics, epilepsy, and forensic aspects of learning disability and challenging behaviour.

\section{Psychotherapy}

Psychotherapy training is often orientated towards psychoanalytic training, although in some schemes, a three-year training in cognitive therapy is available. Trainees usually complete a personal analysis, either through the Scottish Institute of Human Relations or the Institute of Psychoanalysis. Cognitive or analytical psychotherapy training is popular for general psychiatry trainees, who may complete sufficient training to supervise $\mathrm{SHOs}$ at a later stage.

\section{Child and adolescent}

Child and adolescent psychiatry is the most separate of the specialist training programmes and most schemes have their own training programmes, academic seminars and research arrangements. Clinical experience in both central and peripheral placements, plus special experience, is available.

\section{Certificate of Completion of Specialist Training}

Since the introduction of the Calman reforms, the achievement of the CCST marks the end of higher training in psychiatry and the ability to move into a consultant post. CCSTs are available either in single specialities or dual certification between two psychiatric specialities (see Box 3 ).

\section{Other aspects of training}

\section{Academic programme}

A formal programme of seminars is organised during the academic terms, covering topical issues, presentation of audit or research work or a review of the literature on a particular topic. Many individual specialities also have academic input for their own trainees. Joint meetings provide cross-fertilisation of ideas between specialities and the chance for those in small specialities to meet their peers.

Box 3. The Certificate of Completion of Specialist Training (CCST)

Single CCST - all specialities, 3 years

One year special interest training (liaison psychiatry, rehabilitation and substance misuse are recognised)

Dual CCST -4 years

General learning disability oldage psychiatry

Dual CCST -5 years

Forensic general psychiatry

Psychotherapy general psychiatry

Child \& adolescent with another speciality

Application for CCST

Postgraduate dean's office RITA Form G, previously form $\mathrm{C}$ - no charge

Royal College of Psychiatrists CCST notification form $-£ 100$ single, $£ 150$ dual

(Include evidence for recognition of postmembership training, research, overseas placements, etc.)

Specialist Training Authority (STA) application form $-£ 250$

Interviews for consultant posts can take place within three months of CCST dates

The applications to the College and the STA are submitted at the same time and the recommendation for the award of a CCST is forwarded from the College to the STA 
Research

Research may be supervised through the university department or by a research committee, with representation from academic departments, research and development directorates, consultants with a high research profile and trainee representatives. Setting up a network of research supervision is helpful.

\section{Other meetings}

The programme director is responsible for informing trainees about academic meetings held in the area, and relevant courses which the trainee may wish to attend. In the west of Scotland, each trainee can attend a specialist course relevant to their training over a period of one to two years. A successful innovation has been the introduction of the continuing professional development/day release course joint meetings involving trainees and consultants, looking at topical developments in management of difficult clinical problems and debates on ethical issues.

\section{Undergraduate teaching}

Specialist registrars are encouraged to be involved in clinical undergraduate teaching within their own placements and to take up opportunities in multidisciplinary areas. With the changes in the undergraduate curriculum, in many universities there is increased scope for SpRs to become involved in teaching communication skills and in problemorientated teaching and learning.

\section{Opportunities for special experience}

It is useful if each programme director keeps a list of opportunities for special experience within the scheme. This can then be gradually expanded, depending on the availability of training, and provides information as to particular areas appropriate to an individual trainee. This may include attachment to genetics, an epilepsy centre, a neurological sciences institute, a spinal injuries unit, hospice work, psychosexual training or the Mental Welfare Commission. It is also possible for general psychiatry trainees to gain special experience in other specialities, particularly psychotherapy, cognitive-behavioural therapy, forensic psychiatry and learning disability, either as a block placement or as special interest sessions.
All trainees have the opportunity of shadowing managers within the region and attending a management training course for psychiatrists. Exposure to both psychiatric management and systems in other specialities is useful.

\section{Trainees' representation}

Trainees are represented on all the speciality committees which supervise the training schemes in each of the specialities. It is important to have an active trainees' committee which liaises with the programme director and speciality tutors. The more trainees there are involved in the organisation, the more likely that the scheme will run well. The committee also arranges social events and welcomes new trainees to the scheme.

\section{Transition group}

During the last year of training as an $\mathrm{SpR}$, it is helpful to have mechanisms to increase responsibility of the trainee and to prepare them for work as a consultant. The setting up of a transition group for SpRs and newly-appointed consultants has been a valuable experience in the west of Scotland. Also of value is the opportunity to do up to three months locum during their final year.

\section{Flexible training}

In the past 15 years, there has been increasing emphasis on flexible training for those who, because of domestic commitments or other reasons, are unable to work full-time. The introduction of centrally-funded supernumerary flexible training posts (five to eight sessions) has helped prime the system and encourage trusts and training schemes to employ flexible trainees (Report Sub-Committe of ACME, 1992). Psychiatric specialities have always been one of the main users of this scheme, and a recent manpower survey in Scotland suggested that almost $20 \%$ of those training flexibly in the SpR grade are in psychiatry.

Training posts can be produced by splitting full-time posts or reducing sessions, as appropriate. This allows greater flexibility and the opportunity for trainees to increase their sessions. It is also important that flexible training can be extended into flexible working, with increased availability of part-time consultant posts. The current manpower situation in psychiatry is likely to increase this in areas where there are vacant consultant posts.

Approval of flexible training programmes for SpRs, is through the Higher Specialist Training 
Committee and for SHOs through the Basic Specialist Training Committee. All flexible trainees must go through this process. Information on flexible training is available through the College from the Flexible Training Adviser and the Women in Psychiatry Group.

\section{Staff grade psychiatrists}

The staff grade was introduced in 1987 following the publication of Achieving a Balance (Department of Health, 1987), as a service grade to provide an intermediate level of responsibility and a secure hospital career for those unwilling or unable to become consultants. Studies of staff grades both within psychiatry and in other specialities, show that there are major problems in relation to the nature of the grade, the lack of career advice, exclusion from career progression and isolation. A survey in Scotland (Rippen \& Buckley, 1996) showed that the majority of women were in the staff grade for domestic and family reasons, and many of the men in the grade were overseas graduates, increasingly from Eastern Europe. Most planned to move at some stage, either into the associate specialist grade or back into higher training with the idea of becoming a consultant. About $40 \%$ required further training and the others required continuing professional development.

The College has been supportive to staff grade posts in psychiatry, and the Dean can approve a staff grade post as being of a suitable standard to allow training for membership. The degree to which trusts support staff grades to complete higher training is variable and on the whole is better in Scotland than the rest of the UK. However, staff grade training cannot count towards the total six-year period of training required for a CCST.

\section{Overseas doctors and EEC doctors}

Compared with other specialities, psychiatry has always had fairly small numbers of overseas doctors, mainly because of language problems. The Overseas Doctors Training Scheme at career registrar level has been a success, and this is now being transferred to SpR level.

One of the reasons for the introduction of the CCST was to standardise training in all EEC countries and to allow free movement of doctors. There are increasing opportunities to compare training in different EEC countries and to learn from each others' experience (Hogen \& Lindhart, 1997).

Training in psychiatry in the Republic of Ireland is overseen by the Royal College of Psychiatrists and the training schemes are set up in a similar way to the UK, with local variations related to variations in the health service. There has always been a movement of psychiatric trainees between the UK and the Republic of Ireland, which has been an advantage to both countries, with cross-fertilisation of ideas.

\section{Conclusions - the future}

\section{Relationships with GPs}

Having implemented the Calman reforms, training in psychiatry is likely to reach a steady state. The next challenge is in relation to the implementation of the White Papers and the increasing liaison with general practice. Some training schemes already have close links with general practice, for example, general practitioner trainees at SHO level gain experience in psychiatry, and many psychiatric trainees have completed general practice training including the MRCGP. There is scope for further development at SpR level, and doctors with experience of both specialities are far more likely to work well in producing a National Health Service which provides seamless care between primary and secondary services.

\section{SHO schemes}

Having reorganised higher training, it is now important for psychiatry to look at the configuration of SHO schemes and how training at this level can be improved further, and hence encourage recruitment. It will be interesting to see the effects on recruitment to psychiatry of the changes in the undergraduate curriculum, with the increasing introduction of problem-orientated training. The input of consultants in postgraduate education is critical to develop and improve training. In some areas, educational contracts are used to help manage the consultant contribution to education and training. It is essential to encourage trusts to provide both the time and resources for consultants to take on this important task of training future psychiatrists.

\section{Workforce planning}

Another important issue is that of workforce planning and the availability of part-time posts at all levels. The current flexible training system is not always as flexible as it might be, and the issue of equivalence between part-time and full-time training needs to be reviewed. It would be helpful if the detailed experience of training, rather than the exact time spent in it, could be taken into account when working out 
CCST dates. In relation to the issue of psychiatrists retiring prematurely, usually because of increasing clinical pressures, it might be helpful to have a mechanism which allows people to work part-time and use their managerial, educational or specific clinical skills, rather than having to cover a complete catchment area. It is important that psychiatry takes up the challenge of all these issues if we are to compete with other specialities in the workforce market.

\section{References}

Department of Health (1987) Hospital Medical Staffing 'Achieving a Balance' - Plan for Action. London: Department of Health.
- (1993) Hospital Doctors: Training for the Future Report of the Working Group on Specialist Medical Training (Calman Report). London: Department of Health.

- (1996) A Guide to Specialist Registrar Training (2nd edn). London: Department of Health.

Hogen, F. \& Lindhart, A. (1997) Training in psychiatry: a European perspective. European Archives of Psychiatry and Clinical Neuroscience, 247 (suppl.), S1-S2.

Report Sub-Committee of ACME (1992) Part-Time Training and Working for Doctors in Scotland: Introduction of the Supernumerary Grade. Scottish Office.

Rippen, H. \& Buckley, E. (1996) Educational needs of staff grade doctors and dentists in Scotland: SCPDME. Health Bulletin, July, 318-331.

Royal College of Psychiatrists (1995) College Tutors' Handbook. London: Royal College of Psychiatrists.

- (1998) Higher Specialist Training Handbook (Occasional Paper OP43). London: Royal College of Psychiatrists.

\section{Forthcoming from Gaskell}

\section{Getting the Message Across}

\section{A review of research and theory about disseminating information in the NHS}

Claire Palmer and Julie Fenner

An essential requirement of effective clinical practice is the rapid dissemination of research findings and their incorporation into practice. The usual dissemination method for NHS-generated research is publication in a professional journal and presentation at conferences. Occasionally educational strategies might be applied. There is increasing evidence that these strategies are often ineffective and that much of this new information is not adopted into practice for many years, if at all.

This book is aimed at all those in the long chain between the source of new information in the NHS (be it policy, research or managerial innovations) and its intended target audience. The book includes overviews of relevant research and theory to support the development of more effective dissemination strategies in the NHS.

June 1999, Paperback, ISBN 190124236 6, £10.00

Book Sales, Royal College of Psychiatrists, 17 Belgrave Square, London SW1X 8PG. Telephone +44 (0)171 2352351 ext. 146, fax +44 (0)171 2451231. Credit card orders can be taken over the telephone.

See the latest information on College publications on the Internet at: 